\title{
Reservoir: a dirty word in HIV
}

At the First International Workshop on HIV Persistence During Therapy last month in the French West Indies, recently identified therapeutic targets were put under a magnifying glass. Roger Pomerantz of Thomas Jefferson University boldly opened the symposium with the statement that it would take "hubris to think we could eradicate this disease." Following this potentially pessimistic beginning, the attendees began to evaluate the current state of their combined efforts.

The existence of a persistent and stable reservoir of HIV-1 has significant clinical implications, as the virus can continue to replicate even in the setting of optimal suppression with highly active antiretroviral therapy (HAART). Since HIV-1 appears to be incurable with HAART therapy alone, significant effort -

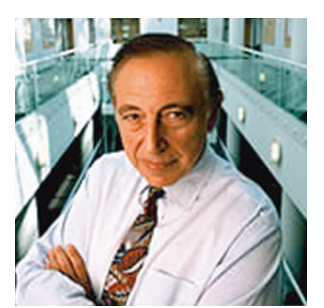

Robert Gallo: Redefining the terms presenters. Sites discussed in St. Martin as potential reservoirs include macrophages, $\mathrm{CD}^{+}{ }^{+}$and $\mathrm{CD}^{+} \mathrm{T}$ cells, NK cells, CD $14^{\text {lo }} \mathrm{CD} 16^{\text {hi }}$ monocytes, $\mathrm{B}$ cells, the CNS, and the male and female genital tracts; those discerned not to be involved include peripheral blood dendritic cells, erythrocytes, and endo- and ectocervical cells.

As some of these data were presented, there was an ongoing evolution of the term "reservoir," spurred by Robert Gallo of the Institute of Human Virology. Gallo told the JCI, "On and on we hear about this or that cell may be infected: the entire colon, all epithelia and endothelium; but we come down to the fact that it is just macrophages and $\mathrm{CD}^{+} \mathrm{T}$ cells. Those cells circulate all over the body." $\mathrm{He}$ continued, "People here are talking about it as if it was some special place, and it just doesn't exist. in fact, this whole meeting of some of the field's top scientists is dedicated to understanding the virus and the cells in which HIV can hide. Even in patients with prolonged suppression of viremia, some free virus can exist in the plasma. The question remains: How can such an ever-changing infection be treated when it can't be found and killed everywhere it exists?

Simon Wane-Hobson of Institut Pasteur likened HIV to royalty: "HIV is not the sultan of substitution, as polio and influenza viruses do it better; but HIV is the regent of recombination." The wily nature of the virus, and the impossibility of eradicating every infected cell, entered into nearly every talk. However, presenters had differing ideas on just where to target eradication techniques.

The idea of the "sanctuary site," or reservoir, in which HIV actively replicates and can evade protease inhibitors or HAART was introduced by many
Find wherever there is infection and you will find $\mathrm{CD}^{+} \mathrm{T}$ cells and macrophages and that's it. It's a convenient term, but I think it's misleading." Gallo conceded that it is important to talk about cervical and seminal fluid, as it is harder to specifically target drugs to those locales, but said that "it's not going to be the pineal gland - formerly claimed by René Descartes to be the site of the soul - or the upper left quadrant of the spleen. I'm trying to get people away from this notion that it's a specific site."

As a result of Gallo's early interjection, later presenters, like Pomerantz and Edward Berger of the NIH, revised their slides to reflect the evolution of the term.

When discussing Mario Stevenson's presentation that showed that vesicles containing retrovirus within macrophages were infectious, Gallo reluctantly but laughingly amended his objection to the use of "reservoir," stating, "I think he definitively showed that is a sacred sanctuary!"

In addition to the refinement of definitions, presentations focused on new strategies for keeping viremia under control. "Super-HAART" regimens, therapeutic vaccines coupled to structured treatment interruption, deacetylase inhibitors, and targeted immunotoxins were some of many potential therapies put forward for consideration.

Will a cure ever be possible in this lifetime? "It is essential, in my mind, for people to see if we can develop a cure within the developed nations in the best places for care, under the best circumstances," said Gallo. "There wouldn't be this many people working on it if we thought it would never happen. I actually think it's impossible, but I enjoy working on things that are impossible. Next week I'm going to try to fly off the Empire State Building!"

Pointing to Pomerantz, Gallo added,

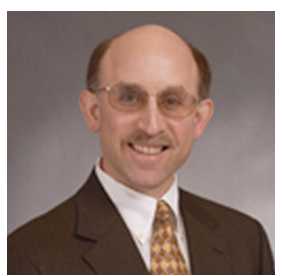

Is the glass halfempty or half-full for Roger Pomerantz? "He thinks its possible. That's for him to push." Despite his somewhat negative opening statement, Pomerantz spoke at length with the JCI about his excitement for the potential therapeutic targets discussed at the meeting. And after Gallo's encouraging nod, he added, "There's only two questions the world wants answered: when will there be a vaccine, and when will there be a cure? And if you raise the white flag now and give up, then you're saying it's just like the rest of internal medicine, meaning cures are very, very difficult. And we can't do that."

Ushma Savla, St. Martin 